\title{
RELATIONSHIPS BETWEEN OVERWEIGHT, OBESITY AND PHYSICAL FITNESS OF THIRTEEN AND FOURTEEN-YEAR-OLD MACEDONIAN ADOLESCENT
}

\author{
Vujica Živkovic ${ }^{1}$, Lidija Todorovska ${ }^{2}$, Lence A. Veličkovska ${ }^{1}$, \\ Serjoža Gontarev ${ }^{1}$, and Ruždija Kalac ${ }^{1}$ \\ ${ }^{1}$ Faculty of Physical Education, Sport, and Health \\ Ss. Cyril and Methodius University, Skopje, Macedonia \\ ${ }^{2}$ Department of physiology and anthropology, Medical faculty, \\ Ss. Cyril and Methodius University, Skopje, Macedonia
}

\section{SUMMARY}

The aim of this research is to determine the fitness level of the Macedonian adolescents, including adolescents from both sexes with different variables of their body mass indexes (BMI). The research has been carried out on 1835 adolescents and students from 19 elementary schools throughout Central and Eastern Macedonia. The sample (average age being $13.43 \pm .5$ ) was split into two sub-samples in relation to their gender, 933 being male and 902 being female respondents. Five anthropometric measurements (IBP methodology) were used in the research, in which the body fitness was analyzed using the following parameters: estimating motor skills applying seven tests of the Eurofit fitness testing battery; body composition by applying the BIA; aerobic capacity by applying a 3-minute step test. The results have been statistically analyzed using the SPSS, v. 20.0 for Windows (variance analysis, Spearman's correlation analysis and the test). The percentage of the overweight children, classified according to the BMI is equal to $31 \%$ of the Macedonian adolescents of the same age. Both male and female respondents with a high or an increased BMI have lower muscle mass percentage and show poor test results in the evaluation of the body strength, explosive power, speed, agility and coordination, as well as a low aerobic capacity.

Key Words: aerobic capacity, body composition, Body Mass Index, EUROFIT, Macedonian adolescents.

\section{INTRODUCTION}

Obesity is a global epidemic, a situation declared by the World Health Organization [WHO] almost fifteen years ago (WHO, 2000). If childhood obesity has developed, and especially so in the adolescent age, it remains into adulthood (Biro \& Wien, 2010; Janssen, Katzmarzyk, \& Ross, 2002; WHO, 2003). Also, it is considered a risk factor for cardiovascular disease, diabetes, asthma and some socio-psychological disorders in older age (Freedman, Mei, Srinivasan, Berenson, \& Dietz, 2007; Reillly et al., 2003). The fact that in the last three decades the number of overweight children in the world has repeatedly increased, so that today there are over 150 million obese children (In- ternational Obesity Task Force [IOTF], 2004). Although obesity is mostly prevalent in highly developed countries it is expanding rapidly in developing countries and transitional countries (IOTF, 2004; Lobstein \& Frelut, 2003).

Obesity is a multifactorial problem that is influenced by a variety of areas including heredity, social conditions, lifestyle, dietary habits, level of physical activity and differences in upbringing that exist in different environments (National Institutes of Health of USA, 2000). Its actual level of prevalence differs depending on the geographical region (Jackson-Leach \& Lobstein, 2006).

Physical fitness has been shown to be another important issue from a Public Health perspective, 
both in adults (Metter, Talbot, Schrager, \& Conwit, 2002; Myers et al., 2002) and in children and adolescents (Ortega et al., 2008, Ortega, Ruiz, Castillo, \& Sjostrom, 2008). Studies examining the relationship between weight status and health-related physical fitness in youth have often reported a decrease in fitness with increasing BMI (Brunet, Chaput, \& Tremblay, 2007; Casajus, Leiva, Villarroya, Legaz, \& Moreno, 2007; Deforche et al., 2003; Fogelholm Jackson-Leach \& Lobstein, 2008; Graf et al., 2004; Haerens, Deforche, Maes, Cardon, \& De Bourdeaudhuij, 2007; Huang \& Malina, 2007; Kim et al., 2005a, 2005b; Prista, Maia, Damasceno, \& Beunen, 2003).

Monitoring the nutritional status and physical fitness of children and adolescent of the population represents a particularly important and useful activity that indicates the adequacy of the process of growth and development of children and youth, helping in understanding the present, and can serve as a prognostic factor in their future health. Up until now, there was a limited amount of quantitative data regarding Macedonia especially regarding organized and systematic monitoring of nutritional status of certain population groups, primarily children and youth. Often, previous research focused on a specific group or region, using various and oftentimes non-standard criteria, reference values or standards.

According to the presented researches as well as to the fact that the period of early adolescence age is particularly exposed to intensive changes in hormonal status, the main aim of this research is to determine the connection of the fitness with the different status of weight, categorized by the BMI size and the percent of body fat in Macedonian adolescents.

\section{METHODS}

\section{Sample of respondents}

The research was realized on a sample of 1835 adolescents of Macedonian nationality, from 19 primary schools from the central and east part of the Republic, out of which 8 are in rural and 11 are in urban environment. The sample has been divided into two sub-samples by gender -933 of the respondents are boys and 902 respondents are girls. The average age of the respondents of both genders was $13.43 \pm .5$ years.

The study included students for whom their parents had given consent to take part in the research, who were psychically and physically healthy and who regularly attended the classes of physical and health education. The respondents were treated in accordance with the Helsinki Declaration. Measurements were realized in March, April and May 2012, in standard school conditions at regular classes of physical and health education. The measurement was realized by experts from the area of kinesiology and medicine, previously trained to perform functional tests and to take anthropometric measures.

\section{Anthropometric measures and body composition}

Measuring of the anthropometric measurements was realized at the recommendations given by IBPInternational Biology Program (Lohman et al., 1988). For estimation of the morphologic characteristics the following anthropometric measures have been applied:

- BH - body height in standing position (cm),

- BW - body weight (kg),

- CUA - circumference of the upper arm (cm)

- CT - circumference of the thight $(\mathrm{cm})$,

- BMI - body mass index.

Components of the body composition have been determined by the method of bioelectrical impedance (measuring of the electric conductivity - Bioelectrical Impedance Analysis [BIA]). The measuring was realized by a Body Composition Monitor, model "OMRON - BF511", by means of which we have measured the body weight, fat tissue percent and muscular mass percent. Prior to commencing the measurement we had entered the parameters of gender, years and body height of the respondent in the Body Composition Monitor. In order to provide better precision of the results obtained from the estimation of the body composition, prior to each measuring, we ensured that the preconditions recommended by American College of Sports Medicine [ACSM] (2005) and Heyward (2006) had been fulfilled.

\section{Evaluation of Physical Fitness}

Prior to starting the study, the researchers involved in the project undertook training sessions in order to guarantee the standardization, validation, and reliability of the measurements (Moreno et al., 2003). Seven tests, forming part of the EUROFIT battery, validated and standardized by the European Council, were applied in the following order:

- SR - Sit and Reach test. With the subject seated on the floor and using a standardized support, the maximum distance reached with the tip of the fingers by forward flexion of the trunk is measured. Test indicative of amplitude of movement or flexibility.

- HG - Hand Grip test. With the use of a digital Takei TKK 5101 dynamometer (range, 1-100 
$\mathrm{kg}$ ), the maximum grip strength was measured for both hands.

- SBJ - Standing broad jump test. The maximum horizontal distance attained, with feet together, was measured. This test evaluates lower limb explosive-strength.

- BAH - Bent Arm Hang test. A standardized test was used to measure the maximum time hanging from a fixed bar. This test estimates the upper limb endurance- strength.

- SU30 - Sit-ups 30 s. Maximum number of sit ups achieved in 30 seconds. This test measures the endurance of the abdominal muscles.

- SR4x10 - Shuttle run $4 \times 10 \mathrm{~m}$. This test provides an integral evaluation of the speed of movement, agility and coordination. The subject does four shuttle runs as fast as possible between 2 lines
10 meters apart. At each end the subject places or picks up an object (a sponge) beside the line on the floor.

- ST3 - 3 minute step test. The aerobic capacity has been estimated by means of a 3-minute step test. The respondent had a task, for 3 minutes, to get up and get down of a bench $30.5 \mathrm{~cm}$ high, in four cycles (up, up, down, down), with standardized rhythm of 96 beats in a minute (bmp), which was dictated by the metronome. Before beginning of the test we have measured the heart frequency, whereas the children, even in the stand-by state had sub maximal value in terms of the age, were not exposed to burdening. The heart rate was measured by means of the monitor Polar RS800 for registration of the heart frequency.

\section{TABLE 1}

Characteristics of the study sample by gender.

\begin{tabular}{|c|c|c|c|c|c|c|c|}
\hline & \multicolumn{2}{|c|}{ Boys $(n=933)$} & \multicolumn{2}{|c|}{ Girls $(n=902)$} & \multicolumn{2}{|c|}{ Total $(n=1835)$} & \multirow{2}{*}{$p$} \\
\hline & $M$ & $S D$ & $M$ & $S D$ & $M$ & $S D$ & \\
\hline Age (year) & 13.43 & .50 & 13.44 & .50 & 13.43 & .50 & ns \\
\hline CUA $(\mathrm{cm})$ & 24.98 & 3.67 & 24.74 & 3.28 & 24.86 & 3.49 & ns \\
\hline $\mathrm{CT}(\mathrm{cm})$ & 50.90 & 6.84 & 50.90 & 7.18 & 52.37 & 6.37 & .000 \\
\hline $\mathrm{BH}(\mathrm{cm})$ & 165.00 & 8.82 & 160.11 & 6.44 & 162.63 & 8.13 & .000 \\
\hline BW (kg) & 58.95 & 14.19 & 55.35 & 11.20 & 57.20 & 12.95 & .000 \\
\hline $\mathrm{BF}(\%)$ & 18.67 & 8.01 & 26.70 & 7.12 & 22.61 & 8.58 & .000 \\
\hline $\mathrm{FM}(\mathrm{kg})$ & 11.68 & 7.18 & 15.40 & 6.96 & 13.50 & 7.31 & .000 \\
\hline FFM (kg) & 47.59 & 9.62 & 40.02 & 5.63 & 43.92 & 8.79 & .000 \\
\hline BMI $\left(\mathrm{kg} / \mathrm{m}^{2}\right)$ & 38.17 & 3.14 & 32.92 & 2.44 & 35.59 & 3.85 & .000 \\
\hline MM $(\%)$ & 21.57 & 3.99 & 21.52 & 3.95 & 21.54 & 3.97 & $\mathrm{~ns}$ \\
\hline $\mathrm{SBJ}(\mathrm{cm})$ & 174.06 & 28.94 & 135.95 & 24.43 & 155.61 & 32.92 & .000 \\
\hline SU30 (No) & 19.16 & 4.73 & 15.56 & 4.39 & 17.41 & 4.91 & .000 \\
\hline $\mathrm{BAH}(\mathrm{s})$ & 13.26 & 13.11 & 4.03 & 5.54 & 8.79 & 11.17 & .000 \\
\hline HG (kg) & 43.56 & 17.80 & 32.22 & 11.40 & 38.05 & 16.06 & .000 \\
\hline $\mathrm{SR}(\mathrm{cm})$ & 14.44 & 7.45 & 19.08 & 7.66 & 16.70 & 7.90 & .000 \\
\hline SR4x10 (s) & 12.50 & 1.43 & 14.04 & 1.59 & 13.24 & 1.69 & .000 \\
\hline \multirow[t]{2}{*}{ ST3 (bmp) } & 134.99 & 17.81 & 154.19 & 16.05 & 144.28 & 19.50 & .000 \\
\hline & $n$ & $\%$ & $n$ & $\%$ & $n$ & $\%$ & $p$ \\
\hline Normal weight & 599 & 65.50 & 646 & 71.60 & 1245 & 69.30 & .049 \\
\hline Overweight & 252 & 27.00 & 197 & 21.80 & 446 & 23.70 & ns \\
\hline Obese & 141 & 7.50 & 59 & 6.50 & 141 & 6.90 & ns \\
\hline
\end{tabular}

Legend: M - Mean; SD - Standard deviation; $\mathbf{p}$ - Probablity; ns - Non-significant; CUA - Circumference of the upper arm; CT - Circumference of the thight; BH - Body hight; BW - Body weight; BF - Body fat; FM - Fat mass; FFM - Fat-free mass; BMI - Body mass index; MM - Muscular mass; SBJ - Standing broad jump test; SU30 - Sit-ups 30 s; BAH - Bent Arm Hang test; HG - Hand Grip test; SR - Sit and Reach test; SR4x10 - Shuttle run $4 \times 10 \mathrm{~m}$; ST3 - 3 minute step test.. 
TABLE 2

Correlation quotients of BMI and body fat percentage with anthropometric and physical parameters (boys).

\begin{tabular}{|c|c|c|c|c|c|c|c|c|}
\hline & \multicolumn{4}{|c|}{ BMI } & \multicolumn{4}{|c|}{$\mathrm{BF}$} \\
\hline & $\mathrm{N}$ & $\mathrm{O}$ & $\mathrm{OB}$ & $\mathrm{T}$ & $\mathrm{N}$ & $\mathrm{O}$ & $\mathrm{OB}$ & $\mathrm{T}$ \\
\hline \multicolumn{9}{|c|}{ Anthropometrical parameters } \\
\hline CUA $(\mathrm{cm})$ & $.896^{* *}$ & $.907^{* *}$ & $.913^{* *}$ & $.907^{* *}$ & $.600^{* *}$ & $.644^{* *}$ & $-.695^{* *}$ & $.616^{* *}$ \\
\hline $\mathrm{CT}(\mathrm{cm})$ & $.868^{* *}$ & $.886^{* *}$ & $.890^{* *}$ & $.883^{* *}$ & $.650^{* *}$ & $.674^{* *}$ & $.725^{* *}$ & $.655^{* *}$ \\
\hline $\mathrm{BH}(\mathrm{cm})$ & $.150^{* *}$ & $.271^{* *}$ & $252^{* *}$ & $.244^{* *}$ & $-.248^{* *}$ & $-.108^{* *}$ & $-.078^{*}$ & $-.173^{*}$ \\
\hline BW (kg) & $.859^{* *}$ & $.897^{* *}$ & $.898^{* *}$ & $.882^{* *}$ & $.450^{* *}$ & $.531^{* *}$ & $.589^{* *}$ & $.483^{* *}$ \\
\hline MM $(\%)$ & $-.489^{* *}$ & $-.447^{* *}$ & $-.523^{* *}$ & $-.465^{* *}$ & $-.917^{* *}$ & $-.888^{* *}$ & $-.903^{* *}$ & $-.905^{* *}$ \\
\hline FM $(\mathrm{kg})$ & $.858^{* *}$ & $.891^{* *}$ & $.900^{* *}$ & $.876^{* *}$ & $.955^{* *}$ & $.935^{* *}$ & $.948^{* *}$ & $.944^{* *}$ \\
\hline FFM (kg) & $.513^{* *}$ & $.636^{* *}$ & $.631^{* *}$ & $.587^{* *}$ & $-.088^{* *}$ & $.083^{* *}$ & $.140^{* *}$ & -.004 \\
\hline \multicolumn{9}{|c|}{ Physical parameters } \\
\hline $\mathrm{SBJ}(\mathrm{cm})$ & $-.264^{* *}$ & $-.188^{* *}$ & $-.251^{* *}$ & $-.216^{* *}$ & $-.633^{* *}$ & $-.551^{* *}$ & -.570 & $-.598^{* *}$ \\
\hline SU30 (No) & $-.120^{* *}$ & $-.083^{* *}$ & $-.125^{* *}$ & $-.112^{* *}$ & $-.386^{* *}$ & $-.337^{* *}$ & -.353 & $-.369^{* *}$ \\
\hline BAH (s) & $-.501^{* *}$ & $-.499^{* *}$ & $-.568^{* *}$ & $-.505^{* *}$ & $-.723^{* *}$ & $-.695^{* *}$ & -.718 & $-.722^{*}$ \\
\hline $\mathrm{HG}(\mathrm{kg})$ & $.155^{* *}$ & $.236^{* *}$ & $.236^{* *}$ & $.202^{* *}$ & $-.194^{* *}$ & $-.091^{* *}$ & -.066 & $-.147^{* *}$ \\
\hline $\mathrm{SR}(\mathrm{cm})$ & $.073^{* *}$ & .006 & .030 & .024 & $.085^{* *}$ & $.067^{*}$ & .062 & $.061^{*}$ \\
\hline SR4x10 (s) & $.184^{* *}$ & $.129^{* *}$ & $.168^{* *}$ & $.165^{* *}$ & $.476^{* *}$ & $.402^{* *}$ & .421 & $.448^{* *}$ \\
\hline ST3 (bmp) & $.275^{* *}$ & $.229^{* *}$ & $.274^{* *}$ & $.233^{* *}$ & $.512^{* *}$ & $.488^{* *}$ & .496 & $.489^{* * *}$ \\
\hline
\end{tabular}

Legend: BMI - Body mass index; BF - Body fat; CUA - Circumference of the upper arm; CT - Circumference of the thight; BH - Body hight; BW - Body weight; $\mathbf{M M}$ - Muscular mass; FM - Fat mass; FFM - Fat-free mass; SBJ - Standing broad jump test; SU30 - Sit-ups 30 s; BAH - Bent Arm Hang test; HG - Hand Grip test; SR - Sit and Reach test; SR4x10 - Shuttle run $4 \times 10$ m; ST3 - 3 minute step test; N - Normal weight; O - Overweight; OB - Obese; ${ }^{* *}=p<0.01 ;^{*}=p<0.05$.

\section{Definition of weight status}

Four weight status groups were established in this study: underweight, normal weight, overweight and obesity. Participants were categorized according to the international gender and age-specific BMI (kg/ $\mathrm{m}^{2}$ ) cut-off points (Cole, Bellizzi, Flegal, \& Dietz, 2000; Cole, Flegal, Nicholls, \& Jackson, 2007). These points have been particularly established for children and adolescents aged from 2 too 18 years, separately for males and females and for .5 year age groups. These cutoff values are based on percentiles passing at age 18 years through BMI: $18.5 \mathrm{~kg} / \mathrm{m}^{2}$ for underweight, $25 \mathrm{~kg} / \mathrm{m}^{2}$ for overweight, and $30 \mathrm{~kg} / \mathrm{m}^{2}$ for obesity (Ibid).

\section{Statistical analysis}

The data are presented as frequencies (percentage) for categorical variables and mean $(S D)$ for continuous variables. Gender differences in fitness and anthropometric characteristics were analyzed by one-way analysis of variance (ANOVA). Categorical data (weight status) were analyzed using the $\chi^{2}$ - test. Relationships between the variables were determined by Spearman correlation matrices. Adjustment for age was performed using analysis of covariance (ANCOVA) to examine differences in fitness level among weight status groups. Because a significant interaction was found for weight status and gender in relation to all fitness tests $(p<$ $.05)$, all the analyses were performed separately for boys and girls. Bonferroni's adjustments were used for pair wise comparisons. All the analyses were performed using the Statistical Package for Social Sciences software (SPSS, v. 20.0 for Windows; SPSS Inc., Chicago, IL, USA), and values of $p<.05$ were considered statistically significant.

\section{RESULTS}

Table 1 displays the characteristics of the sample being used in this research. The results from the analysis of the variance (Table 1 ) show that in variables the average age, arm circumference and BMI there are no statistically significant differences existing between boys and girls, while in all other variables there are statistically significant differences in terms 
of gender $(\phi>.00)$. Distribution of the statement of normal, overweight and obesity in adolescents, estimated through BMI, by age and by gender are also displayed in Table 1. Values of Chi-square test $\left(\chi^{2}=\right.$ 6.024; $p=.049)$ indicate that there are statistically significant differences in the level of nutrition between boys and girls. Percentage values show that higher percentage of boys is with moderate high and high BMI (fat).

Table 2 and 3 shows the correlation quotients of BMI and body fat percentage with anthropometrical and physical parameters, parameters for estimation of body composition and test for estimation of fitness in respondents of both genders. We can see from the tables that all anthropometrical parameters and parameters for estimation of the body composition (except for the muscle mass percentage) show statistically significant positive correlation in both genders (range from .12 to .91) with the body mass index and the body fat percentage. Statistically significant negative correlation (range from -.11 to -.72) is determined of BMI with body fat percentage by the "Standing long jump", "Sit-ups 30 sec.", "Bent arm hang", "Shuttle run 4 x 10 meters" and " 3 minute step test". Only the "Handgrip" test showed positive correlation with BMI, while there was no statistically significant correlation determined of BMI with the body fat percentage in the test "Seat and reach". The correlation quotients are a bit higher of the body fat percentage with variables for estimation of the anthropometrical parameters, body composition and fitness test in terms of BMI and them. In both genders the highest negative correlations of BMI and the body fat percentage are shown by fitness tests "Bent arm hang", "Standing long jump", and "3 minute step test".

Table 4 and Table 5 display the medium values of parameters for estimation of the anthropometrical parameters, body composition and fitness, upon partialization by weight status groups. In both genders there are statistically significant differences determined in all parameters for estimation of the anthropome-

TABLE 3

Correlation quotients of BMI and body fat percentage with anthropometric and physical parameters (girls).

\begin{tabular}{|c|c|c|c|c|c|c|c|c|}
\hline & \multicolumn{4}{|c|}{ BMI } & \multicolumn{4}{|c|}{$\mathrm{BF}$} \\
\hline & $\mathrm{N}$ & $\mathrm{O}$ & $\mathrm{OB}$ & $\mathrm{T}$ & $\mathrm{N}$ & $\mathrm{O}$ & $\mathrm{OB}$ & $\mathrm{T}$ \\
\hline \multicolumn{9}{|c|}{ Anthropometrical parameters } \\
\hline $\mathrm{CUA}(\mathrm{cm})$ & $.888^{* *}$ & $.908^{* *}$ & $.911^{* *}$ & $.897^{* *}$ & $.657^{* *}$ & $.707^{* *}$ & $.700^{* *}$ & $.698^{* *}$ \\
\hline $\mathrm{CT}(\mathrm{cm})$ & $.854^{* *}$ & $.890^{* *}$ & $.888^{* *}$ & $.871^{* *}$ & $.690^{* *}$ & $.744^{* *}$ & $.732^{* *}$ & $.730^{* *}$ \\
\hline $\mathrm{BH}(\mathrm{cm})$ & $.164^{* *}$ & $.177^{* *}$ & $.190^{* *}$ & $.145^{* *}$ & $-.118^{* *}$ & $-.119^{* *}$ & $-.119^{* *}$ & $-.110^{* *}$ \\
\hline BW (kg) & $.872^{* *}$ & $.896^{* *}$ & $.894^{* *}$ & $.887^{* *}$ & $.552^{* *}$ & $.610^{* *}$ & $.595^{* *}$ & $.611^{*+}$ \\
\hline MM (\%) & $-.511^{* *}$ & $-.596^{* *}$ & $-.561^{* *}$ & $-.593^{* *}$ & $-.907^{* *}$ & $-.922^{* *}$ & $-.913^{* *}$ & $-.924^{* * *}$ \\
\hline FM (kg) & $.878^{* *}$ & $.908^{* *}$ & $.899^{* *}$ & $.899^{* *}$ & $.946^{* *}$ & $.956^{* *}$ & $.955^{* *}$ & $.953^{* *}$ \\
\hline FFM (kg) & $.574^{* *}$ & $.580^{* *}$ & $.605^{* *}$ & $-584^{* *}$ & $.076^{* *}$ & $.108^{* *}$ & $.123^{* *}$ & $.130^{* *}$ \\
\hline \multicolumn{9}{|c|}{ Physical parameters } \\
\hline $\mathrm{SBJ}(\mathrm{cm})$ & $-.224^{* *}$ & $-.329^{* *}$ & $-.312^{* *}$ & $-.305^{* *}$ & $-.541^{* *}$ & $-.603^{* *}$ & $-.604^{* *}$ & $-.574^{* *}$ \\
\hline SU30 (No) & $-.085^{* *}$ & $-.160^{* *}$ & $-.155^{* *}$ & $-.147^{* *}$ & $-.307^{* *}$ & $-.372^{* *}$ & $-.377^{* *}$ & $-.339^{*+*}$ \\
\hline $\mathrm{BAH}(\mathrm{s})$ & $-.498^{* *}$ & $-.589^{* *}$ & $-.570^{* *}$ & $-.533^{* *}$ & $-.667^{* *}$ & $-.728^{* *}$ & $-.722^{* *}$ & $-.695^{* *}$ \\
\hline $\mathrm{HG}(\mathrm{kg})$ & $.209^{* *}$ & $.174^{* *}$ & $.192^{* *}$ & $.184^{* *}$ & $-.074^{* *}$ & $-.096^{* *}$ & $-.094^{* *}$ & $-.065^{*}$ \\
\hline $\mathrm{SR}(\mathrm{cm})$ & .050 & $.083^{* *}$ & $.067^{*}$ & $.080^{* *}$ & $.098^{* *}$ & $.113^{* *}$ & $.095^{* *}$ & $.123^{* *}$ \\
\hline SR4x10 (s) & $.128^{* *}$ & $.224^{* *}$ & $.205^{* *}$ & $.195^{* *}$ & $.382^{* *}$ & $.449^{* *}$ & $.448^{* *}$ & $.412^{* *}$ \\
\hline ST3 (bmp) & $.233^{* *}$ & $.323^{* *}$ & $.312^{* *}$ & $.274^{* *}$ & $.474^{* *}$ & $.520^{* *}$ & $.518^{* *}$ & $.486^{* *}$ \\
\hline
\end{tabular}

Legend: BMI - Body mass index; BF - Body fat; CUA - Circumference of the upper arm;

CT - Circumference of the thight; $\mathbf{B H}$ - Body hight; BW - Body weight; $\mathbf{M M}$ - Muscular mass; FM - Fat mass; FFM - Fat-free mass; SBJ - Standing broad jump test; SU30 - Sit-ups 30 s; BAH - Bent Arm Hang test; HG - Hand Grip test; SR - Sit and Reach test; SR4x10 - Shuttle run $4 \times 10$ m; ST3 - 3 minute step test; $\mathbf{N}$ - Normal weight; O - Overweight; OB - Obese; ${ }^{* *}=p<0.01 ;{ }^{*}=p<0.05$. 
TABLE 4

Significance of differences in physical fitness components in the various BMI categories in the boys.

\begin{tabular}{|c|c|c|c|c|c|c|c|c|c|}
\hline & \multicolumn{2}{|c|}{1} & \multicolumn{2}{|c|}{2} & \multicolumn{2}{|c|}{3} & \multirow{2}{*}{ F } & \multirow{2}{*}{$p$} & \multirow{2}{*}{$\begin{array}{c}\text { Post hoc pairwise } \\
\text { comparisons }\end{array}$} \\
\hline & $M$ & $S D$ & $M$ & $S D$ & $M$ & $S D$ & & & \\
\hline CUA $(\mathrm{cm})$ & 23.07 & 2.28 & 27.71 & 1.93 & 30.92 & 3.05 & 941.54 & .00 & $1 \& 2 ; 1 \& 3 ; 2 \& 3$ \\
\hline $\mathrm{CT}(\mathrm{cm})$ & 47.89 & 4.56 & 56.78 & 4.49 & 62.25 & 5.07 & 775.50 & .00 & $1 \& 2 ; 1 \& 3 ; 2 \& 3$ \\
\hline $\mathrm{BH}(\mathrm{cm})$ & 162.15 & 8.12 & 164.88 & 8.59 & 165.74 & 9.89 & 16.80 & .00 & $1 \& 2 ; 1 \& 3$ \\
\hline BW (kg) & 50.75 & 7.96 & 67.27 & 8.39 & 82.15 & 11.71 & 1055.89 & .00 & $1 \& 2 ; 1 \& 3 ; 2 \& 3$ \\
\hline $\mathrm{MM}(\%)$ & 37.54 & 3.44 & 34.68 & 3.17 & 32.60 & 3.36 & 227.16 & .00 & $1 \& 2 ; 1 \& 3 ; 2 \& 3$ \\
\hline $\mathrm{SBJ}(\mathrm{cm})$ & 165.74 & 31.89 & 153.87 & 31.82 & 141.91 & 26.95 & 57.92 & .00 & $1 \& 2 ; 1 \& 3 ; 2 \& 3$ \\
\hline SU30 (No) & 18.40 & 4.72 & 17.56 & 4.69 & 15.68 & 4.57 & 22.13 & .00 & $1 \& 2 ; 1 \& 3 ; 2 \& 3$ \\
\hline $\mathrm{BAH}(\mathrm{s})$ & 13.13 & 12.50 & 4.67 & 8.10 & 1.12 & 3.51 & 135.75 & .00 & $1 \& 2 ; 1 \& 3 ; 2 \& 3$ \\
\hline $\mathrm{HG}(\mathrm{kg})$ & 38.23 & 16.16 & 41.97 & 17.73 & 44.35 & 17.81 & 8.70 & .00 & $1 \& 2 ; 1 \& 3$ \\
\hline $\mathrm{SR}(\mathrm{cm})$ & 16.17 & 7.55 & 15.69 & 7.40 & 15.46 & 7.99 & .59 & .56 & \\
\hline SR4x10 (s) & 12.80 & 1.56 & 13.29 & 1.64 & 13.86 & 1.57 & 37.64 & .00 & $1 \& 2 ; 1 \& 3 ; 2 \& 3$ \\
\hline ST3 (bmp) & 139.10 & 19.30 & 145.06 & 18.23 & 152.09 & 19.11 & 37.09 & .00 & $1 \& 2 ; 1 \& 3 ; 2 \& 3$ \\
\hline
\end{tabular}

Legend: M - Mean; SD - Standard deviation; F - F-test; p - Probablity;CUA - Circumference of the upper arm; CT - Circumference of the thight; BH - Body hight; BW - Body weight; MM - Muscular mass; FM - Fat mass; FFM - Fat-free mass; SBJ - Standing broad jump test; SU30 - Sit-ups 30 s; BAH - Bent Arm Hang test; HG - Hand Grip test; SR - Sit and Reach test; SR4x10 - Shuttle run $4 \times 10$ m; ST3 - 3 minute step test; 1 - Normal weight; 2 - Overweight; 3 - Obese.

trical parameters, body composition and tests for estimation of fitness of groups of respondents formed under classification of BMI, except in the "Seat and reach" fitness test.

From the values of the arithmetic means and the level of statistical significance in Tables 4 and 5, one can see that the adolescents of both genders with overweight and obesity achieve better result in the "Handgrip test" compared to the respondents with normal weight $(p<.00)$, but they achieve worse results in other fitness tests. There are no statistically significant differences determined in the "Seat and reach" test between adolescents classified with normal, overweight and increased BMI. No statistically significant differences are determined between male respondents with overweight and obesity in the "Handgrip" fitness test. No statistically significant differences are determined between female respondents with overweight and obesity in the "Bent arm hang" and "Handgrip" fitness tests.

\section{DISCUSSION}

Overweight and obesity in children and adolescents becomes a global epidemic and threatens its spread in Macedonia. 31\% of the 13 and 14-year-old respondents, who were classified according to the BMI criterion, are overeating and obese. Various international studies have also shown similar results (Al-Nakeeb, Duncan, Lyons, \& Woodfield, 2007; Jehn, Gittelsohn, Treuth, \& Caballero, 2006; Ortega et al., 2007; Ostojić, Stojanović, Stojanović, Marić, \& Njaradi, 2011).

Our study results, also, suggest that the male respondents have the tendency to have higher overweight and obesity prevalence in comparison to girls (34.50\% among the males to $28.30 \%$ among the girls). These results are most probably the way they are due to the fact that girls usually take more care of their looks and eating habits. Furthermore, boys spend less time engaging themselves in organized and spontaneous physical activities and more time on sedentary activities (working on the computer, watching television, etc.). However, this has to be verified with further researching.

Over $22 \%$ of the respondents have a body composition that consists of $30 \%$ body fat. The high rate of body fat is related to an increased risk of acute and chronic conditions, especially osteoarthritis, higher blood pressure, diabetes mellitus and cardiovascular diseases. Increased body fat may, also, result in low quality lifestyle, personal and financial hardships for the person having it, his/her family and the society, as well as it can reduce his/her longevity (Aristi- 
TABLE 5

Significance of differences in physical fitness components in the various BMI categories in the girls.

\begin{tabular}{|c|c|c|c|c|c|c|c|c|c|}
\hline & \multicolumn{2}{|c|}{1} & \multicolumn{2}{|c|}{2} & \multicolumn{2}{|c|}{3} & \multirow{2}{*}{ F } & \multirow{2}{*}{$p$} & \multirow{2}{*}{$\begin{array}{l}\text { Post hoc pairwise } \\
\text { comparisons }\end{array}$} \\
\hline & $M$ & $S D$ & $M$ & $S D$ & $M$ & $S D$ & & & \\
\hline CUA $(\mathrm{cm})$ & 23.04 & 2.26 & 27.63 & 1.94 & 30.77 & 3.18 & 846.32 & .00 & $1 \& 2 ; 1 \& 3 ; 2 \& 3$ \\
\hline $\mathrm{CT}(\mathrm{cm})$ & 48.49 & 4.76 & 56.92 & 4.11 & 62.60 & 5.21 & 728.51 & .00 & $1 \& 2 ; 1 \& 3 ; 2 \& 3$ \\
\hline $\mathrm{BH}(\mathrm{cm})$ & 160.58 & 7.14 & 161.99 & 7.91 & 161.59 & 8.12 & 4.75 & .01 & $1 \& 2 ; 1 \& 3$ \\
\hline $\mathrm{BW}(\mathrm{kg})$ & 49.92 & 7.30 & 65.42 & 7.48 & 79.07 & 10.15 & 975.16 & .00 & $1 \& 2 ; 1 \& 3 ; 2 \& 3$ \\
\hline MM (\%) & 35.80 & 3.24 & 33.04 & 3.13 & 30.69 & 3.55 & 206.93 & .00 & $1 \& 2 ; 1 \& 3 ; 2 \& 3$ \\
\hline $\mathrm{SBJ}(\mathrm{cm})$ & 153.27 & 29.27 & 140.24 & 29.82 & 128.00 & 25.68 & 53.58 & .00 & $1 \& 2 ; 1 \& 3 ; 2 \& 3$ \\
\hline SU30 (No) & 17.38 & 4.43 & 16.54 & 4.60 & 14.29 & 5.44 & 21.51 & .00 & $1 \& 2 ; 1 \& 3 ; 2 \& 3$ \\
\hline $\mathrm{BAH}(\mathrm{s})$ & 9.05 & 10.12 & 2.44 & 4.83 & .81 & 3.11 & 98.24 & .00 & $1 \& 2 ; 1 \& 3$ \\
\hline $\mathrm{HG}(\mathrm{kg})$ & 34.59 & 13.49 & 38.24 & 15.46 & 39.55 & 15.54 & 10.97 & .00 & $1 \& 2 ; 1 \& 3$ \\
\hline $\mathrm{SR}(\mathrm{cm})$ & 17.42 & 7.61 & 17.23 & 7.66 & 17.36 & 7.84 & .01 & .99 & \\
\hline SR4x10 (s) & 13.26 & 1.58 & 13.82 & 1.80 & 14.54 & 1.78 & 36.52 & .00 & $1 \& 2 ; 1 \& 3 ; 2 \& 3$ \\
\hline ST3 (bmp) & 144.94 & 19.38 & 150.63 & 17.53 & 158.27 & 17.51 & 30.68 & .00 & $1 \& 2 ; 1 \& 3 ; 2 \& 3$ \\
\hline
\end{tabular}

Legend: M - Mean; SD - Standard deviation; F - F-test; $\mathbf{p}$ - Probablity;CUA - Circumference of the upper arm; CT - Circumference of the thight; BH - Body hight; BW - Body weight; MM - Muscular mass; FM - Fat mass; FFM - Fat-free mass; SBJ - Standing broad jump test; SU30 - Sit-ups 30 s; BAH - Bent Arm Hang test; HG - Hand Grip test; SR - Sit and Reach test; SR4x10 - Shuttle run 4×10 m; ST3 - 3 minute step test; 1 - Normal weight; 2 - Overweight; 3 - Obese.

muno, Foster, Voors, Srinivasan, \& Berenson, 1984; Berenson, McMahon, \& Voors, 1980; Berenson et al., 1982; Dugan, 2008; Williams et al., 1992).

The results of this study clearly show that the extra kilograms and obesity have an influence on the health related fitness among 8 th and $9 \mathrm{~h}$ grade students, at an age of 13 to 14 -years. The negative influence has its highest effect during the cardiorespiratory endurance, body strength, explosive strength, speed, agility and coordination measurement tests. The successful results of most of these tests, in which the fat mass stands in for ballast weight, depend on how the body, itself, moves or on overcoming the body resistance or some parts of the body's resistance. These are motor manifestations which are influenced by the regulation mechanisms of the excitation's intensity and duration (Kurelić, Momirović, Šturm, Radojević, \& Viskić-Štalec, 1975). These mechanisms are obviously more efficient among the youth with balanced weight and height, i.e. lower BMI and body fat values. This concurs with other international researches with a target audience of children aged 5 to 17 years (Baine et al., 2009; Brunet et al., 2007; Casajus et al., 2007; Deforche et al., 2003; FogelholmJackson-Leach \& Lobstein, 2006; Graf et al., 2004; Haerens et al., 2007; Huang \& Malina, 2007; Kim et al., 2005a, b;
Malina et al., 1995; Minck, Ruiter, Van Mechelen, Kemper, \& Twisk, 2000; Prista et al., 2003).

Correlation quotients of the body fat percentage and fitness are a bit higher in boys in terms of girls. On the other side, the correlation quotients of the BMI and fitness are a bit higher in girls in terms of boys.

Macedonian adolescents who are mildly overweight or overweight achieve poorer results in the following tests: tests "Standing long jump", "Sit-ups 30 seconds", "Shuttle run 4x10 meters", " Bent arm hang (s)", and "3 minute step test (bmp)" ( $p<.001)$. Other researches with similar results support the results evaluated in this research (Deforche et al., 2003; Graf et al., 2004; Kim et al., 2005a, b). Regarding flexibility, this research has shown that the respondents who are mildly overweight or overweight achieve similar results as the respondents who have a normal weight do. Two Taiwanese researches can also verify this statement. However, the results of some researches carried out in the Western countries indicate that overweight girls had achieved better results when it comes to flexibility than normally weighing girls, whereas the same can not confirmed for the results of the male respondents (Prista et al., 2003).

Regular physical activity and a high intake of low-carbohydrate and poly-saccharides reduces the risk 
of obesity, and sedentary lifestyle and intake of high-calorific food which is low in nutritional content, increases the risk of obesity in children. Studies indicate that the choice of healthy food for children in the family and school reduces the risk of obesity, while sweetened beverages also increases the risk of obesity. The diet should be based on foods with a low energy value (fruits and vegetables) and whole grains (which are a good source of fiber).

The obtained data point to scientific planning and development of curriculum for the subject of physical and health education in order to optimize the ratio of the quantity of subcutaneous fat and muscle mass, which will create an opportunity for the maximization of engine operation in a wide range of capabilities, especially in the areas of strength and endurance (Katić, 2003). The purpose of physical education at this age, among other things, should be to reduce fat and increase muscle mass, primarily the large muscle groups.

Teaching should be filled with content that will achieve the stated objectives, properly directing motor development and most importantly - to assist in the proper functioning of the health status of the student.

\section{CONCLUSIONS}

This work is an actual research of prevalence of overweight and obesity of children and adolescents in the central and eastern part of Republic of Macedonia based on population approach, putting accent on the prevention. The results indicate that more than 2 children, out of 10 , are overweighed and more than one children out of 10 is obese. It affects the prevalence of obesity in the period of adulthood. The prevalence of overweight and obesity based on BMI in Macedonian adolescents is $31 \%$. In terms of gender differences of Macedonian adolescents, boys show higher percentage of overweight and obesity.

Macedonian adolescents with a mildly high or a high BMI have: reduced aerobic capacity, decreased muscle mass percentage, higher percentage of body fat and show poor results in the tests which determine their physical fitness. The adolescents who are mildly overweight or overweight achieve poorer results in the "Standing long jump", "Sit-ups 30 seconds", "Shuttle run 4x10 meters", "Bent arm hang (s)" tests, however, they achieve similar results regarding their flexibility. "Handgrip (kg)" is the only test with positive results.

Correlation quotients of the body fat percentage and fitness are a bit higher in boys in terms of girls. On the other side, the correlation quotients of the BMI and fitness are a bit higher in girls in terms of boys.

\section{ACKNOWLEDGMENTS}

We hereby express our great gratitude to the adolescents who took part in this study, as well as to their parents and teachers for their cooperation. Special gratitude to the councils of the municipality of Strumica, Kisela Voda and to the Faculty of Physical Education, Sport and Health in Skopje which provided funds for realization of this study.

\section{REFERENCES}

American College of Sports Medicine. (2005). Health-related physical fitness as sessment manual. Baltimore, MD: Lippincott Williams and Wilkins.

Al-Nakeeb, Y., Duncan, M. J., Lyons, M., \& Woodfield, L. (2007). Body fatness and physical activity levels of young children. Annals of Human Biology, 34(1), 1-12. doi: 10.1080/03014460601079886; PMid: 17536750

Aristimuno, G. G., Foster, T. A., Voors, A. W., Srinivasan, S. R., \& Berenson, G. S. (1984). Influence of persistent obesity in children on cardiovascular risk factors: The Bogalusa heart study. Circulation, 69(5), 895-904. doi: 10.1161/01.CIR.69.5.895; PMid: 6705165

Baine, B., Gorman, D., Kern, C. J., Hunt, B. S., Denny, S. G., \& Farris, W. J. (2009). Relationship between Body Mass Index and motor skills of children. Exhibit Hall RC Poster Sessions (Tampa Convention Center).

Berenson, G. S., McMahon, C. A., \& Voors, A. W. (1980). Cardiovascular risk. factors in children: The early natural history of atherosclerosis and essential bypertension. New York, NY: Oxford University.

Berenson, G. S., Webber, L. S., Srinivasan, S. R., Voors, A. W., Harska, D. W., \& Dalferes, E. R. (1982). Biochemical and anthropometric determinants of serum b- and pre-blipoproteins in children: The Bogalusa heart study. Arteriosclerosis, 2, 324-334. doi: 10.1161/01.ATV.2.4.325

Biro, F. M., \& Wien, M. (2010). Childhood obesity and adult morbidities. American Journal of Clinical Nutrition, 91(5), 1499S-1505S. doi: 10.3945/ ajcn.2010.28701B; PMid: 20335542; PMCid:PMC2854915

Brunet, M., Chaput, J. P., \& Tremblay, A. (2007). The association between low physical fitness and high body mass index or waist circumference is increasing with age in children: the 'Quebec en Forme' project. International Journal of Obesity, 31(4), 637-643. 
Casajus, J. A., Leiva, M. T., Villarroya, A., Legaz, A., \& Moreno, L. A. (2007). Physical performance and school physical education in overweight Spanish children. Annals of Nutrition and Metabolism, 51(3), 288-296. doi: 10.1159/000105459; PMid: 17627091

Cole, T. J., Bellizzi, M. C., Flegal, K. M., \& Dietz, W. H. (2000). Establishing a standard definition for child overweight and obesity worldwide: international survey. British Medical Journal, 320, 1240-1243. doi: 10.1136/bmj.320.7244.1240; PMid: 10797032; PMCid: PMC27365

Cole, T. J., Flegal, K. M., Nicholls, D., \& Jackson, A. A. (2007). Body mass index cut offs to define thinness in children and adolescents international survey. British Medical Journal 335(7612), 194-197. doi: 10.1136/ bmj.39238.399444.55; PMid: 17591624; PMCid: PMC1934447

Deforche, B., Lefevre, J., De Bourdeaudhuij, I., Hills, A. P., Duquet, W., \& Bouckaert J. (2003), Physical fitness and physical activity in obese and non obese Flemish youth. Obesity Research, 11(3), 434-441. doi: 10.1038/oby.2003.59; PMid: 12634442

Dugan, S.A. (2008), Exercise for preventing childhood obesity. Physical Medicine and Rehabilitation Clinics of North America, 19(2), 205216. doi: 10.1016/j.pmr.2007.11.001; PMid: 18395644

FogelholmJackson-Leach, R., \& Lobstein, T. (2006), Estimated burden of paediatric obesity and comorbidities in Europe. Part 1. The increase in the prevalence of child obesity in Europe is itself increasing. International Journal of Pediatric Obesity, 1, 26-32. doi: 10.1080/ 17477160600586614; PMid: 17902212

Freedman, D. S, Mei, Z, Srinivasan, S. R, Berenson G. S, \& Dietz, W. H. (2007). Cardiovascular risk factors and excess adiposity among overweight children and adolescents: the Bogalusa hearth study. Journal of Pediatrics, 150(1), 12-17. doi: 10.1016/j.jpeds.2006.08.042; PMid: 17188605

Graf, C., Koch, B., Kretschmann-Kandel, E., Falkowski, G., Christ, H., Coburger, S., ... Dordel, S. (2004). Correlation between BMI, leisure habits and motor abilities in childhood (CHILT-project). International Journal of Obesity and Related Metabolic Disorders, 28(1), 22-26. doi: 10.1038/sj.ijo.0802428; PMid: 14652619

Haerens, L., Deforche, B., Maes, L., Cardon, G., \& De Bourdeaudhuij I. (2007). Physical activity and endurance in normal weight versus overweight boys and girls. Journal of Sports
Medicine and Physical Fitness, 47(3), 344-350. PMid: 17641603

Huang, Y. C., \& Malina, R. M. (2007). BMI and health related physical fitness in Taiwanese youth 9-18 years. Medicine \& Science in Sports \& Exercise, 39(4), 701-708. doi: 10.1249/ mss.0b013e31802f0512; PMid: 17414809

International Obesity Task Force. (2004). Childhood obesity. Report, 1-5.

Jackson-Leach, R., \& Lobstein, T. (2006) Estimated burden of paediatric obesity and co-morbidities in Europe. Part 1. The increase in the prevalence of child obesity in Europe is itself increasing. International Journal of Pediatric Obesity 1(1), 26-32. doi: 10.1080/17477160600586614; PMid: 17902212

Janssen, I., Katzmarzyk, P. T, \& Ross, R. (2002). Body mass index, waist circumference and health risk. Evidence in support of current National Institutes of Health Guidelines. Arch Intern Med, 162(18), 2074-1079. doi: 10.1001/ archinte.162.18.2074; PMid: 12374515

Jehn, M. L, Gittelsohn, J., Treuth, M. S., \& Caballero, B. (2006). Prevalence of overweight among Baltimore city schoolchildren and its associations with nutrition and physical activity. Obesity, 14(6), 989-993. doi: 10.1038/ oby.2006.113; PMid: 16861603

Katić, R. (2003). Identification of motor circuits as a prerequisite programming kinesiology education for children 7-9 years of age. Collegium Antropolpgicum, 27(1), 351-360. PMid: 12974165

Kim, E., Hwang, J. Y., Woo, E. K., Kim, S. S., Jo, S. A., \& Jo, I. (2005a). Body mass index cutoffs for underweight, overweight, and obesity in South Korean schoolgirls. Obesity Research, 13(9), 15101514. doi: 10.1038/oby.2005.183; PMid: 16222050

Kim, J., Must, A., Fitzmaurice, G. M., Gillman, M. W., Chomitz, V., Kramer, E., ... Peterson, K. E. (2005b). Relationship of physical fitness to prevalence and incidence of overweight among schoolchildren. Obesity Research, 13(7), 12461254. doi: 10.1038/oby.2005.148; PMid: 16076995

Kurelić, N., Momirović, K., Šturm, J., Radojević, Đ., \& Viskić-Štalec, N. (1975). The structure and development of the morphological and motor dimensions of the young. Belgrade, Serbia: Fakultet za fizičko vaspitanje.

Lobstein, T, \& Frelut, M. L. (2003) Prevalence of overweight among children in Europe. Obes Res, 4(4),195-200. doi: 10.1046/ j.1467-789X.2003.00116.x 
Malina, R. M., Beunen, G. P., Classens, A. L., Lefevre, J., Eynde Vanden, B. V., Renson, R., ... Simons, J. (1995). Fatness and physical fitness of girls 7 to 17 years. Obesity Research, 3(3), 221-231. dpo: 10.1002/j.1550-8528.1995.tb00142.x; PMid: 7627770

Metter, E. J, Talbot, L. A, Schrager, M., \& Conwit, R. (2002). Skeletal muscle strength as a predictor of all-cause mortality in healthy men. J Gerontol A Biol Sci Med Sci, 57(10), B359-B365. doi: 10.1093/gerona/57.10.B359; PMid: 12242311

Minck, M. R., Ruiter, L. M., Van Mechelen, W., Kemper, H. C., \& Twisk, J. W. (2000). Physical fitness, body fatness, and physical activity: the Amsterdam growth and health study. American Journal of Human Biology, 12(5), 593-599. doi: 10.1002/1520-6300(200009/10)12:5<593::AIDAJHB3>3.0.CO;2-U; doi: 10.1002/ 1520-6300(200009/10)12:5<593::AIDAJHB3>3.3.CO;2-L

Moreno, L., Joyanes, M., Mesana, M., GonzalezGross, M., Gil. C., ... Marcos, A. (2003). Harmonization of anthropometric measurements for a multicenter nutrition survey in Spanish adolescents. Nutrition, 19(6), 481486. doi: 10.1016/S0899-9007(03)00040-6

Myers, J., Prakash, M., Froelicher ,V., Do, D., Partington, S., \& Atwood, J. E. (2002). Exercise capacity and mortality among men referred for exercise testing. $N$ Engl J Med, 346(11), 793-801. doi: 10.1056/NEJMoa011858; PMid: 11893790

National Institutes of Health of USA (2000). Treatment overweught. Washington, DC: U.S. Deperatment of Helath and Human Services.

Ortega, F. B., Artero, E. G., Ruiz, J. R.,VicenteRodriguez, G., Bergman, P., Hagstromer, M., ... Castillo, M. J. (2008a). Reliability of healthrelated physical fitness tests in European adolescents. Int J Obes, 32(Suppl. 5), S49-S57. doi: 10.1038/ijo.2008.183; PMid: 19011654

Ortega, F. B., Ruiz, J. R., Castillo, M. J, \& Sjostrom, M. (2008b). Physical fitness in childhood and adolescence: A powerful marker of health. Int J
Obes, 32(1), 1-11. doi: 10.1038/sj.ijo.0803774; PMid: 18043605

Ortega, F. B., Tresaco, B., Ruiz, J. R., Moreno, L. A., Martin-Matillas, M., Mesa, J. L., ... Castillo, M. J. (2007). Cardio-respiratory fitness and sedentary activities are associated with adiposity in adolescents. Obesity, 15(6), 1589-1599. doi: 10.1038/oby.2007.188; PMid: 17557997

Ostojic, S. M., Stojanovic, M. D., Stojanovic, V., Maric, J., \& Njaradi, N. (2011). Correlation between fitness and fatness in 6-14-year old Serbian school children. Journal of Health, Population and Nutrition, 29(1), 53-60. doi: 10.3329/jhpn.v29i1.7566; PMid: 21528790; PMCid: PMC3075053

Prista, A., Maia, J. A., Damasceno, A., \& Beunen, G. (2003) Anthropometric indicators of nutritional status: implications for fitness, activity, and health in school-age children and adolescents from Maputo, Mozambique. American Journal of Clinical Nutrition, 77(4), 952959. PMid: 12663297

Reillly, J. J., Methwen, E., McDowell, Z. C., Hacking, B., Alexander, D., Stewart, L., \& Kelnar, C. J. H. (2003) Health consequences of obesity. Archives of Disease in Childhood, 88(9), 748-752. doi: 10.1136/adc.88.9.748; PMCid: PMC1719633

WHO. (2000). Obesity: Preventing and managing the global epidemic. Report of a WHO consultation. Technical Report Series No 894. Geneva, Switzerland: WHO.

WHO. (2003). Diet, nutrition and the prevention of chronic diseases. Technical Report Series No 916. Geneva, Switzerland: WHO.

Williams, D. P., Going, S. B., Lohman, T. G., Harsha, D. W., Srinivasin, S. R., Webber, L. S., \& Berenson, G. S. (1992). Body fatness and risk for elevated blood pressure, total cholesterol and serum lipoprotein ratios in children and adolescents. American Journal of Public Health, 82(4), 358-363. doi: 10.2105/AJPH.82.3.358; PMid: 1536350; PMCid: PMC1694353
Received: November 6, 2014

Revision received: December 22, 2014

Accepted: December 22, 2014
Correspondence to: Vujica Živković, PhD Faculty of Physical Education, Sport, and Health,

Blvd. Goce Delcev 9, 1000 Skopje

Republic of Macedonia Phone: 0038970245677 E-mail: zivkovicvujica@yahoo.com 